\title{
malT knockout mutation invokes a stringent type gene-expression profile in Actinobacillus pleuropneumoniae in bronchoalveolar fluid Abdul G Lone ${ }^{1}$, Vincent Deslandes ${ }^{2,3}$, John HE Nash ${ }^{4,5}$, Mario Jacques ${ }^{2,3}$ and Janet I MacInnes*1
}

Address: ${ }^{1}$ Department of Pathobiology, Ontario Veterinary College, University of Guelph, Guelph, Ontario N1G 2W1, Canada, ${ }^{2}$ Groupe de Recherche sur les Maladies Infectieuses du Porc, Université de Montréal, St-Hyacinthe, Québec J2S 7C6, Canada, ${ }^{3}$ Centre de Recherche en Infectiologie Porcine, Université de Montréal, St-Hyacinthe, Québec J2S 7C6, Canada, ${ }^{4}$ Institute for Biological Sciences, National Research Council of Canada, Ottawa, Ontario K1A 0R6, Canada and ${ }^{5}$ Office of Biotechnology, Genomics and Population Health, Public Health Agency of Canada, Ottawa, Ontario K1A 0K9, Canada

Email: Abdul G Lone - alone@uoguelph.ca; Vincent Deslandes - vincent.deslandes@umontreal.ca; John HE Nash - john_nash@phad-aspc.gc.ca; Mario Jacques - mario.jacques@umontreal.ca; Janet I MacInnes* - macinnes@uoguelph.ca

* Corresponding author

Published: 14 September 2009

BMC Microbiology 2009, 9:195 doi:10.1 I86/147/-2180-9-195
Received: 12 January 2009

Accepted: 14 September 2009

This article is available from: http://www.biomedcentral.com/I47I-2/80/9/195

(c) 2009 Lone et al; licensee BioMed Central Ltd.

This is an Open Access article distributed under the terms of the Creative Commons Attribution License (http://creativecommons.org/licenses/by/2.0), which permits unrestricted use, distribution, and reproduction in any medium, provided the original work is properly cited.

\begin{abstract}
Background: Actinobacillus pleuropneumoniae causes contagious pleuropneumonia, an economically important disease of commercially reared pigs throughout the world. To cause this disease, $A$. pleuropneumoniae must rapidly overcome porcine pulmonary innate immune defenses. Since bronchoalveolar fluid (BALF) contains many of the innate immune and other components found in the lungs, we examined the gene expression of a virulent serovar I strain of $A$. pleuropneumoniae after exposure to concentrated BALF for 30 min.
\end{abstract}

Results: In reverse transcription PCR differential display (RT-PCR DD) experiments, A. pleuropneumoniae CM5 exposed to BALF up-regulated, among other genes, a gene predicted to encode LamB, an outer-membrane transport protein of the maltose regulon. To determine the role of the lamB and other genes of the maltose regulon in the pathogenesis of $A$. pleuropneumoniae, knockout mutations were created in the $\operatorname{lamB}$ and malT genes, the latter being the positive transcriptional regulator of the maltose regulon. Relative to the lamB mutant and the wild type, the malT mutant had a significant $(P<0.05)$ decrease in growth rate and an increased sensitivity to fresh porcine serum and high concentrations (more than $0.5 \mathrm{M}$ ) of sodium chloride. In DNA microarray experiments, the BALF-exposed malT mutant exhibited a gene-expression profile resembling that of a stringent type gene-expression profile seen in bacteria facing amino acid or carbon starvation. Genes encoding proteins for protein synthesis, energy metabolism, and DNA replication were down-regulated, while genes involved in stringent response (e.g., relA), amino acid and nucleotide biosynthesis, biofilm formation, DNA transformation, and stress response were up-regulated.

Conclusion: These results suggest that MalT may be involved in protection against some stressors and in the transport of one or more essential nutrients in BALF. Moreover, if MalT is directly or indirectly linked to the stringent response, an important global mechanism of bacterial persistence and virulence in many bacterial pathogens, it might play a role in $A$. pleuropneumoniae pathogenesis. 


\section{Background}

A. pleuropneumoniae causes contagious pleuropneumonia in pigs. The disease can occur in acute, sub-acute, or chronic form [1]. The acute form is characterized by fibrinohemorrhagic pneumonia and the sub-acute and chronic forms by pleuritis with localized necrotizing lesions. The severity and the spread of the disease depend upon the serovar and dose of the strain, and in large measure, upon the immune status of the herd [2].

A. pleuropneumoniae is well adapted to survive and replicate in the host respiratory tract. Its survival and replication requires the expression of genes encoding proteins that protect the bacterium from the host immune response and help it to acquire nutrients. Although RTX (repeats in toxin) toxins, lipopolysaccharide, capsule, and various amino acid and iron transport systems of the bacterium are essential to cause acute disease [3], it is not known how the organism survives in the face of non-cellular innate immune components that form the first line of defence in the lungs [4]. To identify A. pleuropneumoniae genes that are expressed in a medium that mimics, at least in part, the alveolar surface environment of the lungs, we incubated the bacterium in concentrated porcine bronchoalveolar lavage fluid (BALF). In addition to innate immune components, such as collectins, defensins, lysozyme, lactoferrin, and cathelicidin [4], BALF contains surfactant, surfactant-associated proteins, dissolved minerals, and other substances functioning in antioxidation, lipid metabolism, and tissue repair and proliferation in the lungs [5]. Thus, genes expressed by A. pleuropneumoniae in porcine BALF may be important for survival and pathogenesis of the organism.

In RT-PCR DD experiments, A. pleuropneumoniae CM5 exposed to BALF for $30 \mathrm{~min}$ differentially expressed a number of genes, including seemingly a lamB homolog. Consistent with this finding, an earlier study had also reported that $A$. pleuropneumoniae expresses a maltoseinducible, LamB-like outer membrane protein in the host[6]. In E. coli and other gram-negative bacteria, lamB encodes an outer membrane transport protein involved in the transport and metabolism of maltose and maltodextrins. The E. coli maltose regulon is comprised of at least ten genes whose transcription is positively regulated by MalT in the presence of maltotriose derived from either imported maltodextrins or endogenous glycogen [7].

In addition to maltose and maltodextrin transport and metabolism, the genes of the maltose regulon have been associated, in ways less well understood, with virulence in bacteria. For example, MalF, an inner membrane maltose and maltodextrin transport protein, and MalQ, a dextrinyl transferase, have been associated with the expression of cholera toxin and toxin-co-regulated pilus in Vibrio chol- erae [8], as has been LamB with cytopathic effect in enteropathogenic E. coli [9], and adhesion in enteroinvasive E. coli [10] and Aeromonas veronii [11]. Mutants of the malE and malT (transporter) genes in group A Streptococcus are attenuated in their ability to grow in human saliva and to metabolize $\alpha$ glucans and are significantly impaired in their ability to colonize the mouse oropharynx $[12,13]$.

To elucidate the role of the predicted maltose regulon in A. pleuropneumoniae, malT and lamB knockout mutants were constructed and characterized phenotypically. Since MalT is a regulatory protein, the effect of its knockout on the bacterial gene expression level was also determined using DNA microarrays.

\section{Results \\ Expression of maltose-regulon genes by the wild-type A. pleuropneumoniae CM5 in BALF}

Several differentially expressed genes in A. pleuropneumoniae $\mathrm{CM} 5$ exposed to BALF for $30 \mathrm{~min}$ at $37^{\circ} \mathrm{C}$ were first presumptively identified by RT-PCR DD studies. These included genes encoding protein synthesis and hypothetical proteins (APL_068, APL_0363, and APL_0367), in addition to a cell surface protein, LamB (Figure 1). Homologs (>99\% DNA identity) of the 3 hypothetical proteins are present in all the serotypes of A. pleuropneumoniae sequenced so far, suggesting that they might have a role in persistence or pathogenesis, but their levels of expression were not confirmed by real-time PCR or other more direct methods. The level of expression of the lamB gene was estimated by real-time PCR analysis to be 3.3fold higher in BALF- than in BHI-exposed cells (Table 1). Genes of the maltose regulon that were also up-regulated (although some at very low levels) in BALF-exposed cells included malF and malG (encoding the intrinsic membrane proteins of maltose transport system), malP (maltodextrin phophorylase), malQ (amylomaltase) and malK (the ATP-binding cassette of the maltodextrin transporter; Table 1). For further study, we constructed lamB and malT mutants to evaluate the possible role of these genes in the survival of A. pleuropneumoniae CM5.

\section{Growth curves of the malT and lamB mutants}

The malT mutant grew slower than the wild-type organism in BHI. The growth pattern of the lamB mutant was, however, similar to that of the wild-type organism (Figure 2).

\section{Effect of acarbose on the growth of the isogenic malT and lamB mutants of A. pleuropneumoniae CM5}

To assess the effect of the malT knockout mutationon the functioning of the maltose regulon, the parent strain and the malT mutant were grown in acarbose-containing $\mathrm{BHI}$ in the presence or absence of maltose. Acarbose is a competitive inhibitor of maltose transport [14]. Because of the fastidious nutritional requirements of A. pleuropneumo- 
Table I: Differential expression of maltose-regulon genes in BALF-exposed A. pleuropneumoniae CM5

\begin{tabular}{|c|c|c|c|}
\hline Gene & Putative function & $\Delta \Delta \mathbf{C}_{\mathrm{T}} \pm \mathbf{S D}$ & Fold-change* \\
\hline male $(\mathrm{T})$ & Periplasmic maltose binding protein & $-2.82 \pm 0.51$ & $7.06(4.95-10.05)$ \\
\hline malE (R) & & $0 \pm 0.84$ & I (0.55-I.79) \\
\hline malF (T) & Intrinsic membrane protein of maltose transport system & $-2.79 \pm 1.01$ & $6.91(3.43-13.92)$ \\
\hline malF (R) & & $0 \pm 0.39$ & $I(0.76-I .3 I)$ \\
\hline $\operatorname{malG}(\mathrm{T})$ & Intrinsic membrane protein of the maltose transport system & $-2.6 \pm 0.40$ & $6.06(8-4.59)$ \\
\hline malG (R) & & $0 \pm 0.40$ & $I(0.76-1.3 I)$ \\
\hline malK (T) & ATP-binding protein of the maltodextrin transporter & $-1.10 \pm 0.39$ & $2.14(1.6-2.8)$ \\
\hline malK (R) & & $0 \pm 0.76$ & $\mathrm{I}(0.59-1.69)$ \\
\hline $\operatorname{lamB}(\mathrm{T})$ & Maltoporin & $-1.73 \pm 0.46$ & $3.31(2.4 \mid-4.56)$ \\
\hline $\operatorname{lamB}(\mathrm{R})$ & & $0 \pm 0.35$ & $I(0.78-1.27)$ \\
\hline $\operatorname{malP}(\mathrm{T})$ & Maltodextrin phosphorylase & $-0.85 \pm 0.46$ & $1.80(1.31-2.46)$ \\
\hline $\operatorname{malP}(\mathrm{R})$ & & $0 \pm 0.79$ & $\mathrm{I}(0.58-1.72)$ \\
\hline $\operatorname{malQ}(\mathrm{T})$ & Amylomaltase & $-0.96 \pm 0.48$ & $1.94(1.39-2.71)$ \\
\hline malQ (R) & & $0 \pm 0.55$ & $\mathrm{I}(0.68-\mathrm{I} .46)$ \\
\hline $\operatorname{malT}(\mathrm{T})$ & Transcriptional activator of maltose-regulon genes & $-0.75 \pm 0.32$ & $1.68(1.34-2.09)$ \\
\hline malT (R) & & $0 \pm 0.79$ & $\mathrm{I}(0.58-1.72)$ \\
\hline
\end{tabular}

* Fold change is the fold increase or decrease in the level of expression of a gene in the wild type exposed to BALF (target sample, abbreviated as $\mathrm{T}$ ) relative to the level of expression of the gene in the wild type exposed to BHI (calibrator or reference sample, abbreviated as R), as measured by real-time PCR.

Values in the parentheses represent the range in the fold change.

niae, this experiment was performed in BHI instead of a chemically defined medium. After $16 \mathrm{~h}$ of incubation in acarbose-containing BHI that was supplemented with maltose, the wild-type organism reached a significantly lower $\mathrm{OD}_{600}(P<0.05)$ than did the malT mutant (Figure $3)$. In acarbose-containing BHI that was not supplemented with maltose, there was again, a significant difference in the growth of the two strains. The number of wild type and malT mutant cells was lower in acarbose-contain-

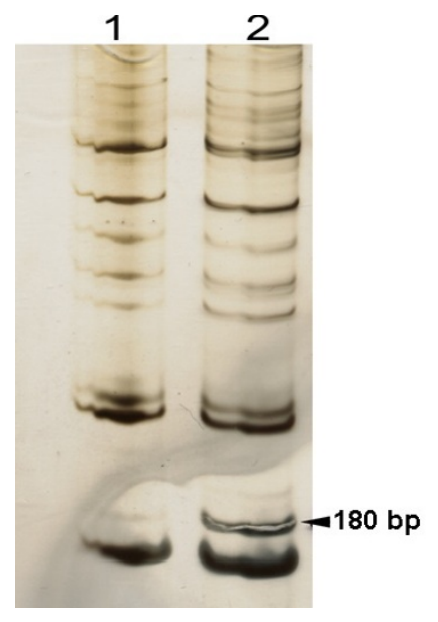

\section{Figure I}

Silver-stained gel comparing $A$. pleuropneumoniae RT-PCR DD products in BHI broth (I) and BALF (2). The arrow points to the band representing a differentially expressed gene, which based on cloning and sequencing (see Methods), appeared to be $\operatorname{lamB}$. ing $\mathrm{BHI}$ than in the BHI containing both maltose and acarbose; however, this difference was not significant (Figure 3). The lamB mutant showed a trend similar to that of the malT mutant grown in the acarbose-containing medium, but the number of lamB mutant cells was lower than that of the malT mutant; however, this difference was not significant.

\section{Survival of the malT and lamB mutants}

Because LamB is a cell surface protein that is positively regulated by MalT, we examined the effects of serum and high concentrations of sodium chloride to better understand the role of these genes in the survival of A. pleuropneumoniae. The percent survival of the malT mutant after incubation at $37^{\circ} \mathrm{C}$ for $1 \mathrm{~h}$ in 90 and $50 \%$ porcine serum was significantly $(P<0.05)$ lower than the percent survival of the wild- type strain (Figure 4 ). There was no significant difference in the survival between the wild-type organism and the lamB mutant in either concentration of the serum. The number of cells of all the three strains (wild-type organism, malT and lamB mutants) surviving in $90 \%$ serum was higher than the number of cells surviving in $50 \%$ serum. E. coli DH5 $\alpha$ did not survive in either concentration of serum.

In the maltose-supplemented BHI containing different concentrations of sodium chloride, the wild type parent, and the malT and lamB mutants showed a significant $(P<$ $0.05)$ decrease in cell numbers after $3 \mathrm{~h}$ of incubation (Figure 5). The decrease in the cell number was least in the wild-type organism and greatest in the malT mutant. In 1 $M$ sodium chloride, the malT mutant decreased in number from an initial count (prior to the addition of the salt to 


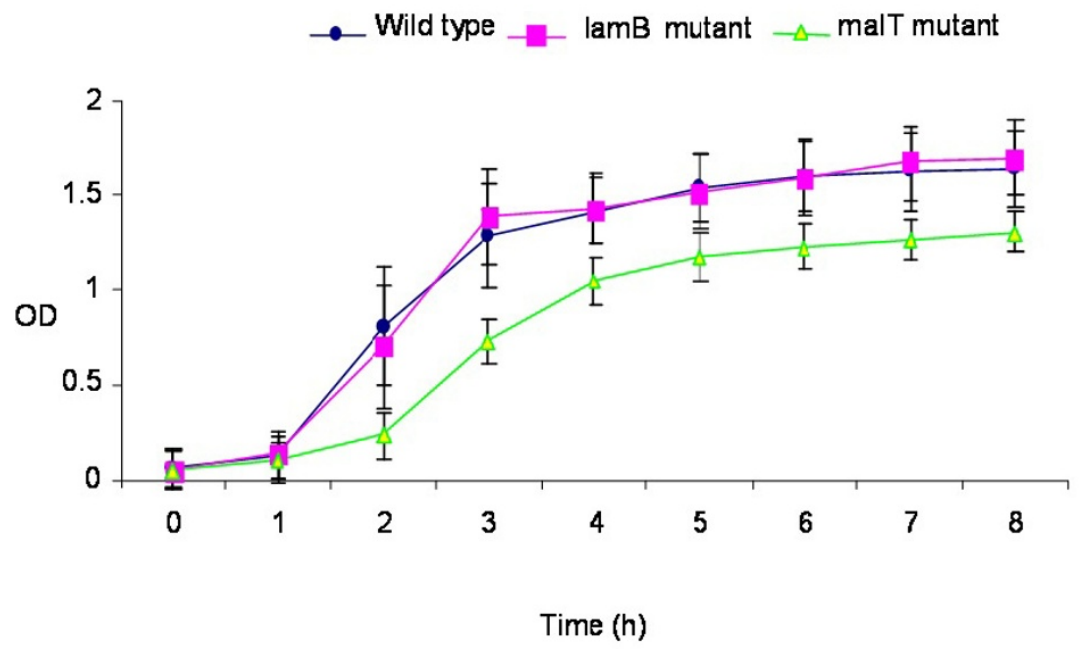

Figure 2

Growth curves of the wild type strain and IamB and malT mutants in BHI broth.

the medium) of $10^{7} \mathrm{CFU} / \mathrm{ml}$ to a final count ( $3 \mathrm{~h}$ subsequent to the addition of the salt to the medium) of 10 $\mathrm{CFU} / \mathrm{ml}$. Even at a $2 \mathrm{M}$ salt concentration, the wild-type organism decreased in number to only $5 \log \mathrm{CFU} / \mathrm{ml}$ from approximately the same initial count as that of the malT mutant. At salt concentrations of $1 \mathrm{M}$ and above, the lamB mutant showed a decline in cell numbers midway between those of the numbers shown by the parent strain and the malT mutant. The wild-type organism, and the malT and lamB mutants were all susceptible to killing by high concentrations of sodium chloride, but this killing was greatest in the malT mutant (Figure 5).

\section{Differential gene expression by the malT mutant in BALF} To understand the basis of the observed phenotypic differences between the malT mutant and the wild-type organism, gene expression profiles of the mutant and parent strains were compared using DNA microarrays. Following the incubation of the exponentially grown cultures of the mutant and wild-type organism in fresh BHI at $37^{\circ} \mathrm{C}$ for $30 \mathrm{~min}$, no significant differences were observed in the

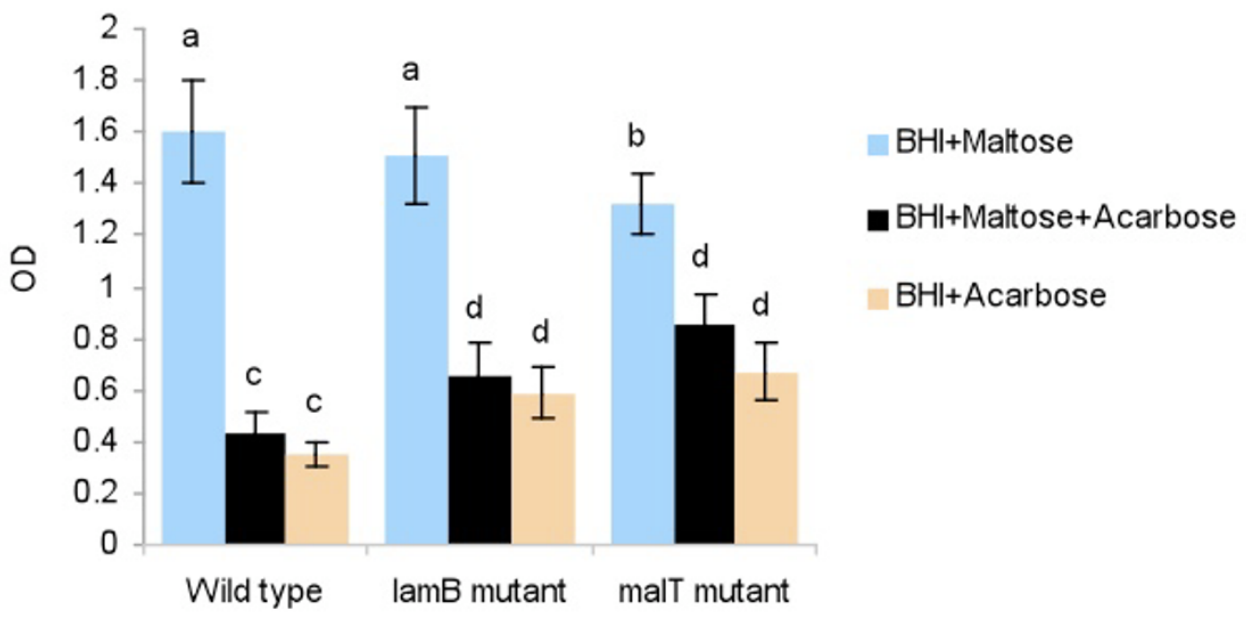

Figure 3

Overnight growth of the wild type strain and the IamB and malT mutants in acarbose or maltose. The bars with same letters on the top do not differ significantly $(P<0.05)$ 


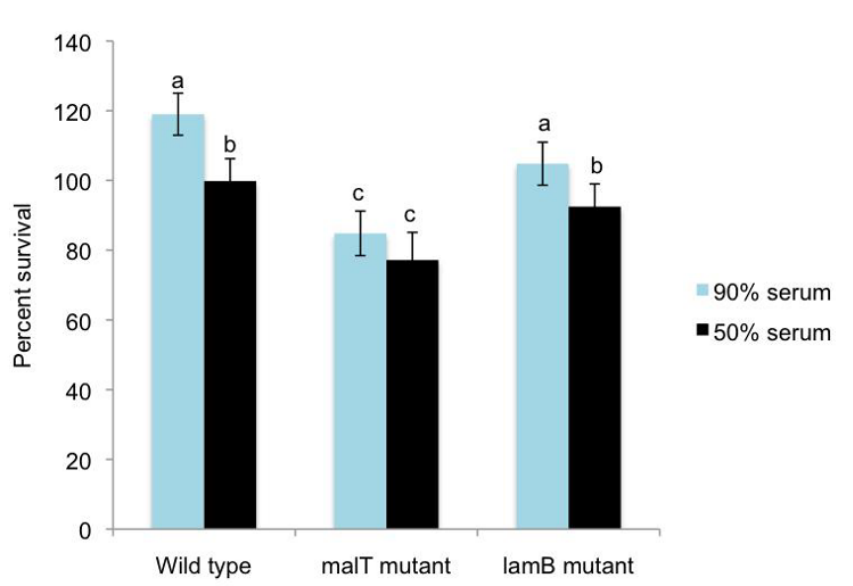

Figure 4

Percent survival of the wild type strain, and the malT and IamB mutants in porcine serum. The percent survival is the fresh-serum-surviving CFU expressed as the percent of CFU surviving in the heat inactivated serum. The strains were incubated in fresh and heat-inactivated serum for I h. The bars with same letters on the top do not differ significantly $(P<0.05)$

gene expression profiles of the two strains even at low delta values. Incubation in BALF, however, resulted in a total of 223 genes being differentially expressed in the malT mutant at a false discovery rate (the percentage of the differentially expressed genes identified just by chance) of $1 \%$. The differentially expressed genes included 104 upregulated and 119 down-regulated genes and 92 of these encoded hypothetical proteins (Table 2, Additional file 1: Analyzed microarray data). In general, the genes encoding proteins involved in energy metabolism and protein bio-

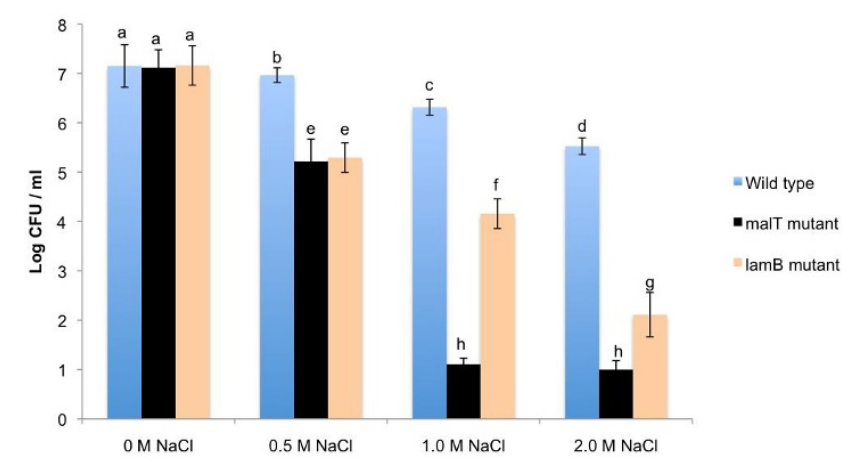

Figure 5

CFU of the wild type strain, and the malT and IamB mutants in different $\mathrm{NaCl}$ concentrations. The strains were incubated for $3 \mathrm{~h}$ in the salt-containing $\mathrm{BHI}$ medium. Before being exposed to $\mathrm{NaCl}$, the strains were grown in maltose-containing $\mathrm{BHI}$. The bars with the same letters on the top do not differ significantly $(P<0.05)$ synthesis were down-regulated (Table 3), while as those involved in amino acid and nucleotide biosynthesis, DNA transformation, and biofilm formation were up-regulated (Table 4). The relA gene encoding a stringent response regulatory protein was also up-regulated in the malT mutant. Though known as an in vivo-expressed RTX toxin, the apxIVA gene was up-regulated by the wild-type strain in BALF [15] and its expression was further increased in BALF in the malT mutant.

Expression of selected genes representing biological functional categories of interest was also measured by realtime PCR analysis (Table 5). A good corroboration in the context of the up- and down-regulation of the genes was found between the microarray and real-time PCR data.

\section{Discussion}

Expression of maltose-regulon genes by BALF-exposed A. pleuropneumoniae CM5

After exposure of A. pleuropneumoniae CM5 to BALF for 30 minutes, a gene that appeared to be $\operatorname{lam} B$ homologue was shown to be up-regulated by the organism in RT-PCR DD experiments (Figure 1). We selected $30 \mathrm{~min}$ for incubation of the organism in BALF, as the medium conditions should remain fairly constant during this time as might be seen in the animal during early infection when there is constant replenishment of alveolar fluid. As shown in real-time PCR studies, the genes encoding intrinsic membrane transport system proteins (MalF and MalG), maltodextrin phosphorylase (MalP), amylomaltase (MalQ), ATP-binding cassette of the maltodextrin transporter (MalK) of the maltose regulon were also up-regulated in BALF, although some at very low levels (Table 1). Comparison of gene expression in BALF- and BHI-incubated cells by DNA microarrays [15] showed that malF and malG were up-regulated in BALF. However, no differential expression was seen in malT, malK, malP or malQ genes. This disparate finding could be because only small quantities of these proteins are required for function, and small changes in gene expression are difficult to detect. For further study, we focused on the lamB and malT genes of the maltose regulon as LamB is a cell surface protein that lies at the host-pathogen interface and MalT is a transcriptional regulator that might control the expression of genes other than those involved in the maltose and maltodextrin transport and metabolism.

\section{malT and lamB are the components of a functional maltose regulon in A. pleuropneumoniae CM5}

All of the strains of A. pleuropneumoniae sequenced so far possess homologs of the maltose regulon genes malEFG, malK-lamB-malM, malT and malPQ. As demonstrated by microarray-based comparative genomic profiling, these genes are present in the reference strains of all 15 serovars of A. pleuropneumoniae [16]. It might be noted that mal- 
Table 2: Number of genes expressed differentially* within a functional category by the BALF-exposed malT mutant

\begin{tabular}{lcc}
\hline Functional category & Up-regulated genes & Down-regulated genes \\
\hline Protein biosynthesis & 2 & 7 \\
Amino acid biosynthesis & 6 & 2 \\
Cofactor biosynthesis & 4 & 8 \\
Biofilm formation & 4 & 0 \\
Nucleotide biosynthesis & 3 & 0 \\
Lipid biosynthesis & 0 & 2 \\
Lipid degradation & 1 & 0 \\
Cell envelope biosynthesis & 3 & 10 \\
Cellular processes & 5 & 2 \\
Central intermediary metabolism & 0 & 4 \\
DNA metabolism & 3 & 6 \\
Energy metabolism & 7 & 18 \\
Protein folding and stabilization & 2 & 2 \\
Regulatory proteins & 7 & 2 \\
Transcriptional regulators & 0 & 5 \\
Secretion and trafficking & 4 & 10 \\
Mobile and extra-chromosomal function & 2 & 0 \\
Unclassified and unknowns & 51 & 119 \\
Total & 104 & \\
\hline
\end{tabular}

* Differential expression of a gene in the malT mutant is relative to the level of expression of the gene in the wild-type organism, as measured in microarray experiments.

Table 3: Protein-synthesis and energy-metabolism genes expressed differentially* by the BALF-exposed maIT mutant

\begin{tabular}{|c|c|c|}
\hline $\begin{array}{l}\text { Type of the product encoded by the differentially } \\
\text { expressed gene }\end{array}$ & Up-regulated genes & Down-regulated genes \\
\hline Ribosomal proteins and their modifiers & rpmE & $r p l Q, r p s Q, r p l l, r p m G$ \\
\hline tRNA base modifiers & queA & alaS, truD, trmU, \\
\hline Transcription and transcription-related factors & & deaD, rnc, rph, nus $A$, nus $B$ \\
\hline Amino acid biosynthetic enzymes & $\operatorname{trpD}, \operatorname{dap} A, \arg D, \operatorname{proC}, \operatorname{leu} C, \mathrm{ilvH}, \mathrm{tyrR}$ & $\operatorname{aroA}, \operatorname{aroB}$ \\
\hline Periplasmic nitrate reductase (nap operon) & & napB, napG, napF, napD, napH \\
\hline Nitrite reductase (nrf operon) & & $n r f B, n r f C$ \\
\hline Dimethyle sulfoxide reducatse (dms operon) & & $d m s A, d m s B$ \\
\hline Hydrogenases & & hyaA, hybB \\
\hline Amino acid catabolism & & sdaA, aspA \\
\hline pyruvate formate-lyase I-activating enzyme & & PflA \\
\hline Glycolysis and gluconeogenesis & gpmB, pepC & FruK \\
\hline TCA cycle enzymes & sucD, IpdA & \\
\hline Non-glucose hexose-monosaccharide metabolism enzymes & $m t / D$ & nagZ \\
\hline Products of central intermediary metabolism & & ureA, $p p x$ \\
\hline ATP synthase & & $a t p C, a t p B$ \\
\hline Formate dehydrogenase & & fdhE \\
\hline Products involved in fermentation & dld, aldA & \\
\hline Regulatory proteins & narP, sixA, gntR, cysB, asnC, gcvA, rseA & $\operatorname{arc} A, i c \mid R$ \\
\hline Cofactors & folA, folP, pdxY, thiH & hemB, chuW, lipA, ispA, ddc, dxs, ispE, iscA \\
\hline
\end{tabular}

* Differential expression of a gene in the malT mutant is relative to the level of expression of the gene in the wild-type organism (reference sample) as measured in microarray experiments. For complete gene names and the fold changes in gene expression see Additional file I: Analyzed microarray data. 
Table 4: Nutrient-acquisition, replication and virulence genes expressed differentially* by the BALF-exposed malT mutant

\begin{tabular}{|c|c|c|}
\hline $\begin{array}{l}\text { Type of the product encoded by the differentially expressed } \\
\text { gene }\end{array}$ & Up-regulated genes & Down-regulated genes \\
\hline Biofilm-formation proteins & pgaA, pgaC, tadF, apfB & \\
\hline Toxin & apxIVA & \\
\hline Factors imparting resistance to antimicrobials & & ostA, ccp \\
\hline Peptidoglycan and LPS biosynthetic enzymes & $c p \times D, m r d A$ & dacA, murA, mltA, dacB, mreD, fbBI, kdsB, gmhA \\
\hline Membrane proteins & ompPI & ompW, oapB \\
\hline Amino acid transporters & & brnQ, sdaC \\
\hline Carbohydrate transporter & $m t \mid A$ & $p t s B, r b s D$ \\
\hline Iron transport proteins & $c b i O$ & exbD2, afuB_2, frpB, yfeC, exbB2 \\
\hline Protein/peptide transport proteins & $d p p F$ & \\
\hline Other cation transporters & & $p t s N$ \\
\hline Cell division & fic & \\
\hline Lipid transporters & $g \mid p F$ & \\
\hline Factors involved in adaptation to unusual environment & relA & \\
\hline DNA transformation & comEA, comF & \\
\hline DNA degradation proteins & $x$ seA & \\
\hline DNA replication, recombination proteins & recG, $r d g C, r e c$ & $x e r C, \operatorname{rec} R$, priB, polA, ligA, recA, \\
\hline Protein-fate proteins & $h t p X, p r l C$ & ecfE \\
\hline Nucleotide metabolism enzymes & purC, purD, purT & \\
\hline Phopholipid and fatty acid biosynthesis and degradation enzymes & $\operatorname{namA}$ & $a c c A, f a b D$ \\
\hline
\end{tabular}

* Differential expression of a gene in the malT mutant is relative to the level of expression of the gene in the wild-type organism (reference sample). For complete gene names and the fold changes in gene expression see Additional file I: Analyzed microarray data.

Table 5: Verification of microarray data by real-time PCR

\begin{tabular}{|c|c|c|c|c|}
\hline Gene & Putative function & $\Delta \Delta \mathbf{C}_{\mathbf{T}} \pm \mathbf{S D}$ & Fold change by real-time PCR & Fold change by microarray' \\
\hline$d m s A(T)$ & $\begin{array}{l}\text { Anaerobic dimethyl sulfoxide reductase chain } \mathrm{A} \\
\text { precursor }\end{array}$ & $3.45 \pm 1.41$ & $0.091(0.03-0.24)$ & 0.15 \\
\hline$d m s A(\mathrm{R})$ & & $0 \pm 0.51$ & $\mathrm{I}(0.69-1.42)$ & \\
\hline$d m s B(\mathrm{~T})$ & Anaerobic dimethyl sulfoxide reductase chain B & $2.54 \pm 1.61$ & $0.17(0.05-0.52)$ & 0.34 \\
\hline$d m s B(R)$ & & $0 \pm 0.46$ & I (0.72-I.38) & \\
\hline $\operatorname{nap} B(\mathrm{~T})$ & Nitrate reductase cytochrome c-type subunit & $2.24 \pm 0.41$ & $0.21(0.15-0.28)$ & 0.17 \\
\hline $\operatorname{nap} B(\mathrm{R})$ & & $0 \pm 0.49$ & I (0.7I-I.40) & \\
\hline $\operatorname{napF}(\mathrm{T})$ & Ferredoxin-type protein NapF & $2.24 \pm 0.46$ & $0.21(0.07-0.61)$ & 0.09 \\
\hline $\operatorname{napF}(\mathrm{R})$ & & $0 \pm 0.47$ & $\mathrm{I}(0.7 \mid-1.39)$ & \\
\hline $\operatorname{napD}(\mathrm{T})$ & Putative napD protein & $2.39 \pm 0.34$ & $0.18(0.14-0.24)$ & 0.18 \\
\hline $\operatorname{napD}(\mathrm{R})$ & & $0 \pm 0.54$ & $\mathrm{I}(0.68-\mathrm{I} .46)$ & \\
\hline ilvH (T) & Acetolactate synthase small subunit & $-2.60 \pm 0.36$ & $6.08(4.68-7.90)$ & 6.14 \\
\hline ilvH (R) & & $0 \pm 0.45$ & $\mathrm{I}(0.70-1.4 \mathrm{I})$ & \\
\hline $\operatorname{pgaA}(\mathrm{T})$ & Biofilm PGA synthesis protein PgaA precursor & $-2.04 \pm 1.08$ & $4.11(1.94-8.70)$ & 8.18 \\
\hline $\operatorname{pg} a A(\mathrm{R})$ & & $0 \pm 0.74$ & I (0.59-I.67) & \\
\hline $\operatorname{pgaC}(\mathrm{T})$ & $\begin{array}{l}\text { Biofilm PGA synthesis } \mathrm{N} \text {-glycosyltransferase } \\
\text { PgaC }\end{array}$ & $-2.47 \pm 0.42$ & $5.54(4.12-7.45)$ & 6.23 \\
\hline $\operatorname{pgaC}(\mathrm{R})$ & & $0 \pm 1.05$ & $\mathrm{I}(0.48-\mathrm{I} .07)$ & \\
\hline apxIVA (T) & RTX toxin protein & $-3.01 \pm 1.12$ & $8.06(3.69-17.61)$ & 6.5 \\
\hline apxIVA (R) & & $0 \pm 0.60$ & $\mathrm{I}(0.65-1.52)$ & \\
\hline relA $(\mathrm{T})$ & GTP pyrophosphokinase & $-0.95 \pm 0.42$ & $2.0(1.44-2.56)$ & 6.30 \\
\hline relA (R) & & $0 \pm 0.59$ & $I(0.66-1.5 I)$ & \\
\hline $\operatorname{lamB}(T)^{2}$ & Maltoporin & $1.03 \pm 0.39$ & $0.49(0.37-0.64)$ & $\mathrm{na}^{3}$ \\
\hline $\operatorname{lamB}(\mathrm{R})$ & & $0 \pm 0.23$ & $\mathrm{I}(0.85-1.17)$ & \\
\hline
\end{tabular}

'Fold change is the fold increase or decrease in the level of expression of a gene in the malT mutant (target sample, abbreviated as $\mathrm{T}$ ) relative to the level of expression of the gene in the wild type (calibrator or reference sample, abbreviated as R) in BALF except for the lamB gene ${ }^{2}$ whose expression was compared in $\mathrm{BHI}$ to examine the effect of the malT knockout mutation on the expression of the lamB gene. ${ }^{3}$ Not applicable. Values in the parentheses represent the range in the fold change. 
tose regulon genes are also present in two other upper respiratory tract pathogens, Mannheimia haemolytica and Haemophilus parasuis. The arrangement of some of these genes in A. pleuropneumoniae, however, differs from that found in E. coli. As in E. coli, MalT appears to be a positive transcriptional regulator of lamB in A. pleuropneumoniae as demonstrated by a two-fold decrease in the expression of lamB in the isogenic malT mutant of $A$. pleuropneumoniae CM5 in BHI supplemented with maltose (Table 5). This finding is consistent with an earlier phenotypic study [6] which reported that $A$. pleuropneumoniae expresses a LamB-like outer membrane protein when maltose is added to BHI agar. Moreover, the A. pleuropneumoniae MalT and LamB has a high degree of amino acid similarity with MalT and LamB homologs of a number of other Gram-negative organisms. Also, MalT has a conserved DNA-binding (LuxR-like C-terminal containing helixturn-helix) motif such as found in the E. coli MalT protein.

To further examine the effect of the malT mutation on the regulation of the maltose regulon, both the wild-type organism and the malT mutant were grown in the presence of acarbose. Acarbose is a pseudo-oligosaccharide similar in structure to maltotetraose and it is a competitive inhibitor of maltose transport in E. coli. It can inhibit maltose uptake only if maltose-transport system is first activated by maltose. Acarbose also inhibits $\alpha$-amylases and $\alpha$-glucosidases and is not degraded by E. coli [14]. In BHI supplemented with maltose, acarbose reduced the growth of the wild-type organism as well as that of the malT mutant (Figure 3). The reduction in the growth might have been caused either by accumulation of toxic levels of acarbose by the bacterial cells or by the inhibition of bacterial glucosidases by the accumulating acarbose, or both. The reduction was, however, significantly $(P<0.05)$ greater in the wild-type organism than in the mutant. This is perhaps due to the increased uptake of acarbose by the wild-type organism, owing to its higher activation of the maltose regulon by the intact malT. On the other hand, the reduction in the growth of the malT mutant could have been due to the non-specific entry of acarbose into the bacterial cells.

As A. pleuropneumoniae CM5 is not amenable to complementation it should be noted that we can not rigorously exclude the possibility that the phenotype exhibited by the malT negative strain was affected by some alteration of another gene that occurred during strain construction, but this is very unlikely. That said, taken together, the above findings suggest that $A$. pleuropneumoniae has a functional maltose regulon similar to that of $E$. coli.
malT is required for optimum survival of $A$. pleuropneumoniae CM5 in serum and high concentrations of sodium chloride

In comparison with the wild-type A. pleuropneumoniae CM5 and lamB mutant, the malT mutant had a significantly decreased ability to survive following incubation in fresh porcine serum for $1 \mathrm{~h}$; the wild-type organism, however, grew in serum to a significantly higher number (Figure 4). As resistance of $A$. pleuropneumoniae to killing by serum is predominantly due to its capsule and LPS $[17,18]$, the decreased survival of the malT mutant in serum could have been due to a change in its cell surface polysaccharides or to an alteration in its general metabolism as indicated by its slower growth in BHI. Similarly, in the presence of sodium chloride concentrations of more than $0.5 \mathrm{M}$, the malT mutant had a significantly $(P<0.05)$ diminished ability to survive in the BHI supplemented with maltose. This result suggests that MalT-regulated genes are required for protection against the high concentrations of sodium chloride in A. pleuropneumoniae (Figure 5). An association has been shown to exist between the components of the maltose regulon, stress response, and hypersomolarity in E. coli [19], but it is not known how the maltose regulon behaves in the presence of an exogenous activator and high concentrations of the sodium chloride.

\section{Differential gene expression of the malT mutant in BALF resembles the stringent type gene-expression profile}

There was no significant difference between the gene expression profile of the parent strain and the malT mutant after incubation of the log-phase cultures in fresh $\mathrm{BHI}$ for $30 \mathrm{~min}$. In BALF, however, 223 genes were differentially expressed by the malT mutant (Table 2). The gene expression profile of the mutant resembled a metabolic downshift; genes encoding protein synthesis, energy metabolism, transport of nutrients and DNA replication were all down-regulated, while those involved in amino acid and nucleotide biosynthesis, biofilm formation (prevalent in A. pleuropneumoniae field isolates [20]), DNA transformation, and the stress response were up-regulated (Tables 3 and 4). This type of gene-expression response mimics the gene-expression profile of the stringent response seen in $E$. coli and other organisms during nutrient deprivation [21-23].

Carbon starvation in E. coli invokes a global gene expression response, resulting in the down-regulation of the genes encoding proteins for the growth and replication of the organism and the up-regulation of the genes encoding proteins for the biosynthesis of amino acids, alternate sigma factors, biofilm components [24], as well as proteins of unknown function [25]. During amino acid starvation, the ratio of uncharged to charged tRNA increases, resulting in ribosome stalling at the A-site of the 50S 
ribosomal subunit. The stalling of the ribosome results in the activation of ribosome-bound RelA. RelA, a synthase and SpoT, a hydrolase with a weak synthase activity, synthesize pppGpp (guanosine 3'-diphosphate,5'-triphosphate) and ppGpp (guanosine 3', 5'-bispyrophosphate) which in turn invoke a global gene expression response including down-regulation of rRNA synthesis, such as seen in the stringent response to nutrient starvation [24].

The increased expression of relA and the changes in the overall gene expression profile of the malT mutant in BALF closely resembled the stringent-response geneexpression profile in other bacteria, including E. coli. Consistent with the notion of a stringent response having a role in A. pleuropneumoniae, all the major stringent response regulatory genes including relA, spoT and $d k s A$ (DnaK suppressor protein) are present in the genome of this pathogen. A malT knockout mutation in A. pleuropneumoniae could result in a stringent response because MalTis linked, directly or indirectly, to the regulation of the stringent response genes, or because it regulates the uptake of nutrient(s) in addition to maltose and maltodextrins. The latter assumption could explain the up-regulation of the lamB gene in BALF as a secondary response to the activation or the up-regulation of MalT for the acquisition of nutrients. The slower growth of the malT mutant and its increased sensitivity to the biological stressors could also be explained by changes in cell surface molecules that result from the inability of the mutant to acquire unknown essential nutrient(s). By balancing nutrient availability with ribosome synthesis through the stringent response, bacteria can control replication, enter into a persistence mode of life, or express virulence factors, depending upon the type of bacteria [26-29].

\section{Conclusion}

Taken together, our data suggest that A. pleuropneumoniae CM5 has a functional maltose regulon similar to that found in E. coli. Although it is likely that these genes have a role in acquisition of nutrients in saliva and in the oropharynx where maltodextrins would be predicted to be found, these studies suggest that the maltose regulon could also play a significant role once the organism enters the lungs. Further, the slower growth rate and increased salt and serum sensitivity of the malT mutant versus $\operatorname{lamB}$ mutant suggests that MalT has a role beyond that of maltose and maltodextrin metabolism in A. pleuropneumoniae. This is perhaps due to the involvement of the MalT in the transport or processing of some essential nutrient(s). This assumption is further supported by the expression of the stringent type transcript profile in the malT mutant in BALF. MalT could also be directly or indirectly linked to the stringent response without being involved in the transport of the essential nutrient(s); however, this remains to be proven. The presence of the maltose-regu- lon genes in all serovars of A. pleuropneumoniae and in related pathogens such as Mannheimia haemolytica and Haemophilus parasuis provides further circumstantial evidence that carbohydrate metabolism mediated by the maltose regulon might play a role in the persistence, if not the pathogenesis of some respiratory tract pathogens.

\section{Methods \\ Bacterial strains and media}

A. pleuropneumoniae CM5 [30], and E. coli strains $\beta 2155$ [31] and DH5 $\alpha$ (Clontech, CA, USA) were used in this study (Tables 6 and 7). A. pleuropneumoniae CM5 was grown either in brain heart infusion (BHI; Becton, Dickinson and Company, Sparks, MD, USA) or Mueller-Hinton ( $\mathrm{MH}$; Becton, Dickinson and Company) medium, supplemented with $0.01 \%(\mathrm{wt} / \mathrm{vol}) \beta$-nicotinamide adenine dinucleotide (NAD) as required. Transconjugation medium consisted of $\mathrm{MH}$ broth with $20 \%$ (wt/vol) sucrose, $10 \%$ equine serum (wt/vol), and $0.01 \%$ NAD (wt/vol). E. coli strains were routinely cultured in LuriaBertani (LB) medium, but in the case of $E$. coli $\beta 2155$, the medium was always supplemented with $1 \mathrm{mM}$ diaminopimelic acid (DAP; Sigma-Aldrich, St. Louis, MO, USA). As required, chloramphenicol was also added at the rate of either 5.0 or $2.5 \mu \mathrm{g} / \mathrm{ml}$.

\section{Collection and concentration of bronchoalveolar lavage fluid}

BALF was collected from ten high-health status pigs of approximately $15 \mathrm{~kg}$ in body weight. After euthanizing the pigs, the lungs of the individual animals were lavaged with $100 \mathrm{ml}$ of PBS (phosphate-buffered saline), and the lung washings were collected and centrifuged to remove cell debris. The contents of the washings were then concentrated with a $5 \mathrm{kDa}$ molecular weight cut off ultra-centrifugal filter device, Vivacell 70 (Vivascience Ltd., Stonehouse, GL, UK), which reduced the volume of the washings to $1 / 20^{\text {th }}$ that of their total initial volume. The concentrated BALF was sterilized by filtration through a $0.22 \mu \mathrm{m}$ membrane filter (Pall Corporation, Ann Arbor, MI, USA) and kept at $-80^{\circ} \mathrm{C}$ for long-term storage. Molecules less than $5 \mathrm{kDa}$ in molecular weight were not concentrated by this method; nevertheless, the fluid still contained these substances in the concentrations found before ultrafiltration.

\section{Reverse-transcription PCR differential display}

The RT-PCR DD method described by McClelland et al. [32] was adapted to identify the differentially expressed genes of A. pleuropneumoniae CM5 in BALF. Briefly, the organism was grown to an $\mathrm{OD}_{600}$ of 0.7 in $\mathrm{BHI}$ at $37^{\circ} \mathrm{C}$, harvested by centrifugation, and an approximately $10^{7}$ colony forming units (CFU) were suspended in either concentrated BALF or fresh BHI. After incubation of the cell suspensions at $37^{\circ} \mathrm{C}$ for $30 \mathrm{~min}$, the bacteria were har- 
Table 6: Bacterial strains, plasmids and primers used in the construction of the malT mutant

\begin{tabular}{|c|c|c|}
\hline Bacterial strains, plasmids or primers & Characteristic or sequence & Source or Remark \\
\hline E. coli DH5a & $\begin{array}{l}\text { F- } \phi 80 l a c Z \Delta M I 5 \Delta(\text { lacZYA-rgF)UI69 deoR recAI } \\
\text { endAI hsdRI7(rk -, mk +) supE44 thi-I gyrA96 } \\
\text { relAI } \lambda \text { - }\end{array}$ & Clonetech \\
\hline E. coli $\beta 2155$ & 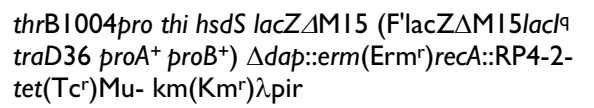 & Reference no. 28 \\
\hline E. coli DH5 $\alpha$-pTOPOPCR-malT & $\begin{array}{l}\mathrm{DH} 5 \alpha \text { harboring PCR } 4-\mathrm{TOPO} \text { containing malT of } \\
\text { A. pleuropneumiae CM5 }\end{array}$ & This work \\
\hline E. coli DH5 $\alpha$ - pTopoMC & $\begin{array}{l}\text { DH5a harboring PCR4-TOPO containing } \\
\text { AmalT::cat }\end{array}$ & This work \\
\hline E. coli DH5 $\alpha$-pEMOC2M & DH5a harboring pEMOC2 containing $\triangle$ malT::cat & This work \\
\hline A. pleuropneumoniae & MalT negative mutant of $A$. & This work \\
\hline CM5 3smalT & pleuropneumonaie CM5 & \\
\hline PCR4-TOPO & A linearized plasmid for cloning PCR product & Invitrogen \\
\hline PEMOC2 & $\begin{array}{l}\text { A conjugation vector based on } \mathrm{pB} \text { Bluesript SK with } \\
\text { mobRP4 and } \mathrm{Cm}^{r}\end{array}$ & Reference no. 31 \\
\hline PTOPOPCR-malT & $\begin{array}{l}\text { PCR4-TOPO containing malT of } A \text {. } \\
\text { pleuropneumiae CM5 }\end{array}$ & This work \\
\hline рTороMC & PCR4-TOPO containing $\triangle m a l T:: c a t$ & This work \\
\hline PEMOC2M & harboring pEMOC2 containing $\triangle$ malT::cat & This work \\
\hline $\begin{array}{l}\text { malT-L } \\
\text { malT-R }\end{array}$ & $\begin{array}{l}\text { ATGCAAGCAACATTTTCAAGA } \\
\text { TTAGCTATACCCCATCATTCTCAA }\end{array}$ & $\begin{array}{l}\text { Primers for amplification of the malT gene of } A \\
\text { pleuropneumoniae CM5 }\end{array}$ \\
\hline stopupmalT-L & $\begin{array}{l}\text { TTAGTTAGTTACGAGCTTTTTCACAC } \\
\text { CGTTT }\end{array}$ & $\begin{array}{l}\text { Primers for generation of a linearized plasmid } \\
\text { containing a deletion of } 900 \text { bp in its malT gene } \\
\text { cloned in pTOPOPCR-malT. }\end{array}$ \\
\hline stopupmalT-R & $\begin{array}{l}\text { TAACTAACTAATGGGAATGGCATCATTTAG } \\
\text { A }\end{array}$ & \\
\hline pnmalT-L & $\begin{array}{l}\text { TCATCTGCAGATGCAAGCAACATTTT } \\
\text { CAAGA }\end{array}$ & $\begin{array}{l}\text { Primers for amplication of the } \Delta \text { malT:: cat and the } \\
\text { insertion of the Pstl and Notl sites into the PCR } \\
\text { product. }\end{array}$ \\
\hline pnmalT-R & $\begin{array}{l}\text { ACAATACAGCGGCCGCTTAGCTATACCCC } \\
\text { ATCATTCTCAA }\end{array}$ & \\
\hline cat-L & CGGTGCCCTGAATGAACT & Primers for the PCR \\
\hline cat-R & AAGCTTCGACGAATTTCTGC & $\begin{array}{l}\text { amplification of omIA-P driven cat gene of } \\
\text { PEMOC2 }\end{array}$ \\
\hline
\end{tabular}

vested by centrifugation and immediately subjected to RNA extraction.

RNA was extracted with Trizol reagent (Invitrogen, Carlsbad, CA, USA) and quantified using RNA 6000 Nano LabChip chips read in a Bioanalyzer 2100 instrument (Agilent Technologies, Santa Clara, CA, USA). The RNA was treated with Turbo RNA-free DNase (Ambion Inc., Austin, TX, USA) according to the manufacturer's instructions.

A total of $0.5 \mu \mathrm{g}$ of RNA and 85 different combinations (Table 8) of arbitrary random primers (GenHunter Corp., Nashville, Tennessee, USA) (Table 9) were used to synthesize cDNA with Moloney Murine Leukemia Virus reverse transcriptase (M-MLV reverse transcriptase; Invitrogen). Reverse transcriptase-negative controls were run with each of the transcription reaction.

One microlitre of the reverse-transcription reaction mixture was used as a template to amplify the cDNA under relaxed PCR conditions. The same primer pairs were used in both the template cDNA synthesis and the random PCR -amplification of the template cDNA. The 20- $\mu$ l PCR reaction mixtures contained $1.5 \mu \mathrm{M}$ of each of the forward and reverse primers, $2.0 \mu \mathrm{l}$ of $10 \times$ PCR buffer, $200 \mu \mathrm{M}$ of dNTP mixture, $4.0 \mathrm{mM} \mathrm{MgCl} 2$, and $2.5 \mathrm{U}$ of Taq DNA polymerase (New England Biolabs, Pickering, ON, Canada). The PCR thermal profile included an initial random primer annealing and extension steps (denaturation $94^{\circ} \mathrm{C}$ for $5 \mathrm{~min}$; primer annealing at $39^{\circ} \mathrm{C}$ for $5 \mathrm{~min}$; and strand extension at $72^{\circ} \mathrm{C}$ for $3 \mathrm{~min}$ ) followed by a 40 -cycle PCR (denaturation $95^{\circ} \mathrm{C}$ for $2 \mathrm{~min}$; primer annealing at $39^{\circ} \mathrm{C}$ for $2 \mathrm{~min}$; and strand extension at $72^{\circ} \mathrm{C}$ for $1 \mathrm{~min}$ ) with a final amplification step of $10 \mathrm{~min}$ at $72^{\circ} \mathrm{C}$. PCR products of the same primer pair were run side by side on $7 \%$ polyacrylamide gels and silver stained, as described elsewhere [33], to visualize the bands representing differentially expressed genes (Figure 1). Bands representing differentially expressed genes were scratched with a 25 gauge needle to harvest DNA. The DNA on the pointed end of the needle was dissolved in a $10 \mu \mathrm{l}$ of PCR-grade water for 5 
Table 7: Bacterial strains, plasmids and primers used in the construction of the lamB mutant

\begin{tabular}{|c|c|c|}
\hline Bacterial strains, plasmids or primers* & Characteristic or sequence & Source or Remark \\
\hline E. coli DH5 $\alpha$-pTOPOFL & $\begin{array}{l}\mathrm{DH} 5 \alpha \text { harboring pCR } 4-\mathrm{TOPO} \text { containing lamB } \\
\text { of } A \text {. pleuropneumia e CM5 }\end{array}$ & This work \\
\hline E. coli DH5 $\alpha$-TOPO $\Delta$ FLcat & $\begin{array}{l}\text { DH5a harboring PCR4-TOPO containing } \\
\text { LlamB::cat }\end{array}$ & This work \\
\hline E. coli DH5 $\Delta$-pEMOC2- $\Delta$ lamB & $\mathrm{DH} 5 \Delta$ harboring $\mathrm{pEMOC2}$ containing $\Delta$ lamB::cat & This work \\
\hline A. pleuropneumoniae CM5 $\Delta \mathrm{lamB}$ & $\begin{array}{l}\text { LamB negative mutant of } A \text {. pleuropneumoniae } \\
\text { CM5 }\end{array}$ & This work \\
\hline PTOPOFL & $\begin{array}{l}\text { PCR4-TOPO containing lamB of } A \text {. } \\
\text { pleuropneumiae CM5 }\end{array}$ & This work \\
\hline TOPO $\Delta$ FLcat & PCR4-TOPO containing $\triangle \mathrm{lamB::cat}$ & This work \\
\hline pEMOC2- $\Delta$ lamB & pEMOC2 containing $\triangle$ lamB::cat & This work \\
\hline $\begin{array}{l}\text { CrosslamB-L } \\
\text { CrosslamB-R }\end{array}$ & $\begin{array}{l}\text { GGTGGCGTAAAAGTAGGAGAT } \\
\text { TGGTCATTATCCACCACCAA }\end{array}$ & $\begin{array}{l}\text { Primers for the PCR amplification of the } \operatorname{lam} B \\
\text { gene of } A \text {. pleuropneumoniae CM5 }\end{array}$ \\
\hline stopuplamB-L & $\begin{array}{l}\text { TTAGTTAGTTACAATATTTTCAACC } \\
\text { CCTGCAC }\end{array}$ & $\begin{array}{l}\text { Primers for the PCR generation of a linearized } \\
\text { plasmid containing a deletion of } 400 \text { bp in the lamB } \\
\text { gene cloned in PTOPOPCR-lamB }\end{array}$ \\
\hline stopuplamB-R & $\begin{array}{l}\text { TAACTAACTAATCACGCACAAGGTTC } \\
\text { AAAAG }\end{array}$ & \\
\hline $\begin{array}{l}\text { PstcrosslamB-L } \\
\text { NotcrosslamB-R }\end{array}$ & $\begin{array}{l}\text { TCATCTGCAGGGTGGCGTAAAAGT } \\
\text { AGGAGAT } \\
\text { ACAATACAGCGGCCGCTGGTCATTATCC } \\
\text { ACCACCAA }\end{array}$ & $\begin{array}{l}\text { Primer sequences for the PCR amplication of the } \\
\Delta \text { lamB::cat and the insertion of the PsTI and Notl } \\
\text { sites into the PCR product }\end{array}$ \\
\hline
\end{tabular}

* The genotype and the source of E. coli DH5 $\alpha$ and the PEMOC2 and PCR4-TOPO plasmids are given in Table 6.

min. This solution of DNA served as a template for a PCR reaction in which the same protocol and the same primers were used as in the differential display PCR that generated the band. The amplified DNA was run on agarose gels and stained with ethidium bromide to visualize the bands for excision. The DNA from the excised bands was purified using QIAquick Gel Extraction Kits (Qiagen Inc., Mississauga, ON, Canada), and the purified PCR products were cloned into the pCR4-TOPO (TOPO TA Cloning Kit, Invitrogen), according to the manufacturer's instructions. The inserts were sequenced by dye terminator cycle sequencing (DNA Sequencing Facility, College of Biologi-

Table 8: Arbitrary random primer pair combinations used in RTPCR DD

\begin{tabular}{lllll}
\hline API7/API8 & API7/API9 & API7/AP20 & API7/AP2I & API7/AP2I \\
API7/AP21 & API7/AP22 & API7/AP23 & API7/AP24 & API7/AP24 \\
API7/AP24 & API8/API8 & API8/API9 & API8/API9 & API8/AP20 \\
API8/AP20 & API8/AP21 & API8/AP2I & API8/AP22 & API8/AP22 \\
API8/AP23 & API8/AP23 & API8/AP24 & API9/API8 & API9/AP20 \\
API9/AP21 & API9/AP22 & API9/AP23 & API9/AP23 & API9/AP24 \\
AP20/API8 & AP20/AP21 & AP20/AP22 & AP20/AP23 & AP20/AP24 \\
AP2I/AP24 & AP2I/API8 & AP2I/AP22 & AP2I/AP23 & AP22/API8 \\
AP22/AP23 & AP22/AP24 & AP23/API8 & AP23/AP24 & AP24/API8 \\
AP4I/API8 & AP4I/AP42 & AP4I/AP43 & AP4I/AP44 & AP4I/AP45 \\
AP4I/AP46 & AP4I/AP47 & AP4I/AP48 & AP42/API8 & AP42/AP43 \\
AP42/AP44 & AP42/AP45 & AP42/AP46 & AP42/AP46 & AP42/AP47 \\
AP43/API8 & AP43/AP44 & AP43/AP45 & AP43/AP46 & AP43/AP47 \\
AP43/AP48 & AP43/AP48 & AP44/API8 & AP44/AP45 & AP44/AP46 \\
AP44/AP47 & AP44/AP48 & AP45/API8 & AP45/AP46 & AP45/AP46 \\
AP45/AP47 & AP45/AP48 & AP46/API8 & AP46/AP47 & AP46/AP48 \\
AP47/API8 & AP47/AP48 & AP47/AP48 & AP47/AP48 & AP48/API8
\end{tabular}

cal Sciences, University of Guelph, Guelph, ON) and compared with the annotated genome sequences of $A$. pleuropneumoniae using Blastx available at http:// blast.ncbi.nlm.nih.gov/Blast.cgi to identify the complete genes.

\section{Construction of the malT knockout mutant}

Based on the genome sequence of A. pleuropneumoniae serovar 1 strain 4074 , primers were designed to amplify the entire malT gene (nucleotides 2118860 to 2121577). The malT PCR product was purified and cloned into

Table 9: Sequences of the arbitrary random primers used in RTPCR DD

\begin{tabular}{ll}
\hline Arbitrary random primer & Sequence \\
\hline API7 & AAGCTTACCAGGT \\
API8 & AAGCTTAGAGGCA \\
API9 & AAGCTTATCGCTC \\
AP20 & AAGCTTGTTGTGC \\
AP21 & AAGCTTTCTCTGG \\
AP22 & AAGCTTTTGATCC \\
AP23 & AAGCTTGGCTATG \\
AP24 & AAGCTTCACTAGC \\
AP41 & AAGCTTACGGGGT \\
AP42 & AAGCTTTGCACCG \\
AP43 & AAGCTTGAAGCGG \\
AP44 & AAGCTTCTCCGGA \\
AP45 & AAGCTTGGCTGAC \\
AP46 & AAGCTTCGGTCCT \\
AP47 & AAGCTTATGCCCG \\
AP48 & AAGCTTGCGGTGA
\end{tabular}


pCR4-TOPO. The resultant plasmid was used as the template in a PCR reaction to produce a linearized plasmid with a deletion of the central 838 bp (bp 922 to bp 1760) of the malT gene. The amplicon was generated using Phusion Taq DNA polymerase (New England Biolabs), a high fidelity DNA polymerase, and the primers that annealed in back to back manner leaving a central 900 bp region of the plasmid malT between them. Following the gel purification of the PCR product, the omlA-P promoter driven chloramphenicol acetyl transferase gene (cat), obtained by PCR amplification of pEMOC2 [34] was blunt-end ligated with the linear plasmid. The resultant circular plasmid with the cat insertion in the malT was designated as pTopoMC. The $\Delta$ malT::cat fragment of pTopoMC was then PCR amplified with forward and reverse primers containing NotI and PstI sites, respectively. The $\Delta$ malT::cat PCR amplicon was gel purified, digested with NotI and Pst I, and cloned into pEMOC2. The resultant plasmid, named pEMOC2M, was electroporated into E. coli $\beta 2155$. pEMOC2M was mobilized from E. coli $\beta 2155$ into A. pleuropneumoniae CM5 using a modification of the filter mating technique described by Oswald et al. [35]. Briefly, overnight cultures of $E$. coli $\beta 2155 /$ pEMOC2M (grown on LB agar containing $25 \mu \mathrm{g} / \mathrm{ml}$ chloramphenicol), and $A$. pleuropneumoniae CM5 (grown on BHI agar) were washed with $2 \mathrm{ml}$ of TNM buffer ( $1 \mathrm{mM}$ Tris-HCl, pH 7.2; $10 \mathrm{mM}$

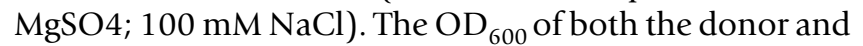
the recipient strains was adjusted to 1 by adding TNM buffer. A $100 \mu$ l volume of the donor and $10 \mu \mathrm{l}$ of the recipient strains were mixed by inversion, and the mixture was centrifuged to pellet the cells, which were washed and then resuspended in $1 \mathrm{ml}$ of fresh TNM buffer. A $50 \mu \mathrm{l}$ volume of the suspension was spotted onto a $0.45 \mu \mathrm{m}$ nitrocellulose filter (Pall Corporation) placed onto the $\mathrm{BHI}$ agar plate containing DAP and $\mathrm{MgSO}_{4}(10 \mathrm{mM})$. After incubation at $37^{\circ} \mathrm{C}$ for $6 \mathrm{~h}$ in an atmosphere of $5 \% \mathrm{CO}_{2}$, the filter was washed with $5 \mathrm{ml}$ of BHI broth. The cells were harvested by centrifugation and re-suspended in 0.5 $\mathrm{ml}$ of BHI broth. After 10-fold serial dilution of the cell suspension, $50 \mu \mathrm{l}$ of cells from each of the dilution was plated onto $\mathrm{BHI}$ agar plates containing chloramphenicol $(5 \mu \mathrm{g} / \mathrm{ml})$. After $24 \mathrm{~h}$ of incubation at $37^{\circ} \mathrm{C}$, the individual colonies appearing on the agar plates were inoculated in $1 \mathrm{ml}$ of $\mathrm{MH}$ broth for further incubation at $37^{\circ} \mathrm{C}$ for 3 $\mathrm{h}$. The cell suspensions of each of the colony were plated on the MH plates containing $2.5 \mu \mathrm{g} / \mathrm{ml}$ chloramphenicol. These plates were incubated at $29^{\circ} \mathrm{C}$ for $48 \mathrm{~h}$. A few colonies from each of the plates were used in colony PCR to verify the integration of the plasmid into the chromosomal malT geneof A. pleuropneumoniae CM5. The primers for the colony PCR were designed so that one primer annealed inside the integrated plasmid and the other on the nearby bacterial chromosomal DNA, thus verifying both plasmid integration and orientation.
The colonies that had undergone plasmid integration at the correct site were selected for the sucrose counter-selection. Selected individual colonies with an integrated plasmid were incubated with constant agitation in $1 \mathrm{ml}$ of $\mathrm{MH}$ broth at $37^{\circ} \mathrm{C}$ until the cultures were slightly turbid. A 1 $\mathrm{ml}$ volume of the counter-selection medium was then added and each of the cultures was incubated for a further $5 \mathrm{~h}$. A $50-\mu \mathrm{l}$ cell suspension from each of the ten-fold serial dilutions $\left(10^{0}\right.$ to $\left.10^{7}\right)$ of these cultures was then plated onto the $\mathrm{MH}$ agar plates containing sucrose (10\%) and chloramphenicol $(2.5 \mu \mathrm{g} / \mathrm{ml})$. After incubation at $37^{\circ} \mathrm{C}$ for $48 \mathrm{~h}$, colonies appearing on the plates were patched onto two BHI agar plates; one containing chloramphenicol $(2.5 \mu \mathrm{g} / \mathrm{ml})$ and the other, ampicillin (100 $\mu \mathrm{g} / \mathrm{ml})$. Chloramphenicol-resistant, ampicillin-sensitive colonies were screened for the second crossover by the PCR using the primers that annealed to the regions of the bacterial chromosome immediately flanking the malT gene. The predicted disruption of the malT gene was confirmed by Southern blotting using the wild type malT gene as a probe and by sequencing the PCR amplicon spanning the cat gene insertion. The primers and plasmids used in the construction of the malT mutant are given in Table 6.

\section{Construction of the lamB knockout mutant}

The construction of the lamB knockout mutant involved the same approach as described for the construction of the malT mutant. A central 379-bp region (bp 518 to bp 897) of the lamB was replaced with the omlA-P driven cat gene and the knockout mutation was confirmed by sequencing and Southern blotting. The primers and plasmids used in the construction of lamB mutant are given in Table 7.

\section{Growth of the mutants}

A. pleuropneumoniae CM5, and its isogenic malT and lamB mutants were grown in $\mathrm{BHI}$ at $37^{\circ} \mathrm{C}$ to monitor their growth. The $\mathrm{OD}_{600}$ of each of the strains was measured every hour from the lag to stationary phase of growth to construct growth curves. For doubling time calculations, culture aliquots were taken at 2, 3, and $4 \mathrm{~h}$ of incubation and the number of CFUs was determined by the plating of 10 -fold dilutions. The data were analyzed using one way analysis of variance (ANOVA) and the means were compared using Tukey's method.

The wild-type organism and the malT and $\operatorname{lamB}$ mutants were also incubated in the BHI containing 0.5\% (wt/vol) acarbose and $0.5 \%$ (wt/vol) maltose to assess the effect of acarbose on the growth of these strains. As the strains grew slowly in the acarbose-containing $\mathrm{BHI}$, their growth was measured after $16 \mathrm{~h}$ of incubation at $37^{\circ} \mathrm{C}$.

\section{Survival of the mutants in serum}

Individual colonies from the overnight cultures of A. pleuropneumoniae CM5, the malT and lamB mutants, and E. coli 
DH5 $\alpha$, were incubated in $5 \mathrm{ml}$ of $\mathrm{BHI}$ at $37^{\circ} \mathrm{C}$ for $2 \mathrm{~h}$. A $1 \mathrm{ml}$ volume of each of the cultures was centrifuged at $10,000 \times g$ for 2 min to pellet the cells before suspension in $1 \mathrm{ml}$ of pre-warmed PBS. One hundred $\mu \mathrm{l}$ of a $1: 10^{5}$ dilution of each culture was added to $900 \mu \mathrm{l}$ of 100 and $55.5 \%$ fresh porcine serum (vol/vol in PBS). As a control, $100 \mu \mathrm{l}$ of $1: 10^{5}$ dilution of each culture was also added to $900 \mu \mathrm{l}$ of heat-inactivated porcine serum (inactivated by heating at $65^{\circ} \mathrm{C}$ for $15 \mathrm{~min}$ ). The number of CFU of each culture was determined after the incubation of the cultures at $37^{\circ} \mathrm{C}$ for $1 \mathrm{~h}$. The number of the CFU surviving in fresh serum was expressed as percent survival according to the following equation:

Percent survival $=\left(\frac{\frac{\mathrm{CFU} \text { at } 1 \mathrm{~h} \text { of incubation inserum }}{\mathrm{CFU} \text { at } 0 \mathrm{~h} \text { incubation }}}{\frac{\mathrm{CFU} \text { at } 1 \mathrm{~h} \text { of incubation in heat in activated serum }}{\mathrm{CFU} \text { at } 0 \mathrm{~h} \text { incubation }}}\right) \times 100$

The experiment was run in quadruplicate, and the percent-survival data were divided by 2 before being converted to arcsin values for the analysis using two-way ANOVA. Means were compared by Tukey's Method.

\section{Survival of the mutants in sodium chloride}

A. pleuropneumoniae CM5, and the malT and lamB mutants were grown to an OD600 of 0.7 in the BHI broth supplemented with $1 \%$ (wt/vol) maltose. Each of these cultures was mixed with fresh BHI containing $4 \mathrm{M}$ sodium chloride in equal proportions for a final concentration of $2 \mathrm{M}$ sodium chloride; cultures containing 1 and $0.5 \mathrm{M}$ of the salt were prepared by the same approach. The number of CFU of each culture was calculated prior to the addition of the salt-containing $\mathrm{BHI}$ and $3 \mathrm{~h}$ subsequent to the incubation at $37^{\circ} \mathrm{C}$ in salt-containing medium. The experiment was repeated four times, and the data obtained were analyzed using ANOVA. Means were compared using Tukey's Method.

\section{Microarray experiments}

The AppChip2 microarray chips used in this study, were an evolved version of the AppChip1 chip, and like its predecessor, was a part of the A. pleuropneumoniae 5b L20 genome sequencing project (NRC-IBS, Ottawa, Canada). For the construction of AppChip2, open-reading-frame (ORF) PCR fragments of 160-nucleotide length and above were spotted in duplicate on the microarray slides. The spots represent 2033 ORFs, covering 95\% of the total ORFS, from the complete genome sequence of the organism. Spotted sheared genomic DNA from A. pleuropneumoniae L20 and porcine DNA were used as controls http:// ibs-isb.nrc-cnrc.gc.ca/glycobiology/appchips e.html. Further details concerning chip production are described elsewhere [36].
Based on the strain (the wild-type organism or the malT mutant) and the incubation medium (BHI or BALF), the microarray experiments involved three types of hybridizations: (1) Cy3-labeled cDNA from the BHI-incubated wild-type organism vs. Cy5-labeled cDNA from the BALFincubated wild-type organism (2) Cy3-labeled cDNA from the BHI-incubated wild-type organism vs. Cy5labeled cDNA from the BALF-incubated malT mutant, and (3) Cy3-labeled cDNA from the BHI-incubated wild-type organism vs. Cy5-labeled cDNA from BHI-incubated malT mutant. Four replications, including dye-swaps, were carried out for each type of hybridization.

cDNA was synthesized in the presence of amino-allyldUTP (Sigma-Aldrich, St. Louis MO, US), random octamer primers (Biocorps, Montreal, QC, Canada), SuperScript II transcriptase (Invitrogen, Carlsbad, CA, US), and the RNA ( $15 \mu \mathrm{g}$ per reaction) obtained from the BALF- and BHI-incubated organisms, according to the method described by Carrillo et al. [37]. Labeling of the cDNA was carried out indirectly with one of the monofunctional NHS-ester dyes Cy3 or Cy5 (GE Healthcare, Buckinghamshire, UK), which binds to the amino-allyldUTP of the cDNA. The dye labeling efficiency of cDNA was determined spectrophotometrically. The data were submitted to the Gene Expression Omnibus (GEO: GSE13006).

\section{Microarray data analysis}

Microarray image and data analysis was carried out using the TM4 Suite of software [38] for microarray analysis, (J. Craig Venter Institute, JCVI, USA) as described elsewhere [36]. Briefly, images were analyzed with Spotfinder v3.1.1. The final intensity of each spot was obtained by subtracting the background intensity from the integral spot intensity (the sum of the intensities of all the spot pixels excluding the saturated ones). The spots with intensities less than one standard deviation above their spot background intensities were eliminated from the downstream analysis, as were the ones with total intensity less than 10000. Replicate spots were analyzed subsequent to the normalization of the data using the LOWESS (locally weighted linear regression) algorithm. The genes that were thus represented by good quality spots (defined by a score assigned by the software based on the number of unsaturated pixels, shape, and signal to noise ratio of the spot) on a minimum of two replicate slides were considered for the downstream analysis using SAM (significance analysis of microarray) to identify the differentially expressed genes. The differentially expressed genes were classified depending upon their biological roles into various functional categories according to the JCVIs Comprehensive Microbial Resources (CMR) database. 
Table 10: Oligonucleotide primers used in the real-time PCR

\begin{tabular}{lll}
\hline Gene & \multicolumn{1}{c}{ Forward primer } & \\
\hline$d m s A$ & ATGTTGCCGGACAAGCACAAGATG & Reverse primer \\
$d m s B$ & AACAGGCATCGATTGCACCGTTAC & TCTCAATGGACAACGGCTACCACA \\
$n a p B$ & GCGCATGGCAACCTAAACATTGGT & ACTTGGACGTGCGTGTTTATTGGC \\
$n a p D$ & TCGGCTAAAGCAAGCTGTCTGTCA & TACAGGCTTTGCAGTAGCGGAAAC \\
$n a p F$ & ACAACCGTCTCCGCAACTTCTACA & TAGCGCAAGTGAAAGCGGACATTC \\
$i l v H$ & GAAAGTTTAACGTTGCGCCGACT & TTGGCTACAACGGAAGAAGCATGG \\
pgaA & GGGAACCGGTGTGAATGCAATGAA & ACGTTCAATATGCTCGGTAGGGCT \\
pgaC & ATCGTTGCGTTACACCAAGCGAAC & TGTTGGAACGTTTGTGAAGACGCC \\
apxIVA & TTGGACTTCACCTGCAAACATGCC & ACCGACATACTTGCCTCTTGCGAT \\
relA & TCGGACAGTTGAAGTGGGAAT & CGGGCAAATATTCCAAAGCGCAGA \\
syp & AAGAAACGCCGAATGATGCACAGG & TGCAAGGCGATTACTCGGTAA \\
lamB & CTGCTAAAGAGAGTTTACCGATGCCA & ACACCTCGATAGCACCACCTTTGT \\
malK & GCGTGTTGCAATTGGACGTACCTT & TGCAACATTACGGGCAGGTAAACG \\
malM & AGCGACACCGTCAAAGACAGAACT & CATGGCTTCGATTTGTCATGCGT \\
malT & TCCTTGATGAGCTTTCGACCCACA & CCAACGTTTGGCTAAATGTGCGGA \\
malP & ACGCTTAGCCGCCTGCTATTTAGA & TAAACCGAGCACCTGCCATTCTCT \\
malQ & ATGCCTATCGGCCTTTACCGTGAT & CACGCATCGCCTTCTTCATGTTGT \\
malE & AACCGATGAAGGACTCACAACCGT & ACCGACAGAGGCATCTAGCACAAA \\
malF & TGCCGTTAATGATTGCCAGCTTCG & TTTCCGCATTCGCCATAGTTGCTG \\
malG & AGTGTTACTCATGCGGACGGAAGT & GCAGCCGCTAAACCAAAGTCTTGT \\
\hline
\end{tabular}

\section{Quantitative real-time PCR}

The parameters of RNA capacity, optimum primer concentration, and the gene dynamic ranges were determined before carrying out the real-time PCR for the relative quantification of the target gene expression. As an endogenous control, the level of prolyl-tRNA-synthetase gene (syp) expression was used to normalize the target gene expression levels, since this gene exhibited the least variation in expression across various conditions in both the microarray and real-time PCR experiments. In the quantitative real-time PCR experiments, three independent biological replicates were tested in triplicate. Calculation of the relative quantification of the target genes was done using the Comparative $\mathrm{C}_{\mathrm{T}}\left(\Delta \Delta \mathrm{C}_{\mathrm{T}}\right)$ method [39]. The protocol of the PCR is given as described below:

Each 20- $\mu$ l PCR reaction mixture contained $2 \times$ Power SYBR Green PCR Master Mix (Applied Biosystems, Streetsville), $100 \mathrm{nM}$ of each of forward and reverse primer, and $5 \mu \mathrm{l}$ of template cDNA. Synthesis of the template cDNA was carried out in a 20- $\mu$ l reaction mixture containing 500 ng RNA, using a High Capacity cDNA Reverse Transcription Kit (Applied Biosystems), which contains random primers for the synthesis of cDNA. The real-time PCR thermal profile included the heat-activation of AmpliTaq Gold DNA Polymerase at $95^{\circ} \mathrm{C}$ for $10 \mathrm{~min}, 40$ cycles of denaturation at $95^{\circ} \mathrm{C}$ for $15 \mathrm{~s}$, and primer annealing and extension at $60^{\circ} \mathrm{C}$ for $1 \mathrm{~min}$. The PCR reactions were carried out in 96-well plates using a StepOnePlus thermocycler (Applied Biosystems, Streetsville, ON, Canada). The primers used in the real-time PCR are given in Table 10.

\section{List of abbreviations}

BALF: bronchoalveolar lavage fluid; BHI: Brain Heart Infusion; $\mathrm{CFU}$ : colony forming unit(s); $\mathrm{NaCl}$ : sodium chloride; NAD: $\beta$-nicotinamide adenine dinucleotide; ORF: Open Reading Frame; PAG: polyacrylamide gel; PCR: polymerase chain reaction; RT-PCR DD: reversetranscription PCR differential display; vol: volume, wt: weight.

\section{Authors' contributions}

AGL and JIM conceived and designed the experiments. AGL conducted the experiments, carried out the data analysis, and drafted the manuscript. VD carried out microarray hybridization experiments and data analysis. JHEN designed and fabricated the microarray chip, Appchip2. MJ also helped in the study design and critically revised the manuscript. All the authors contributed to the final manuscript preparation and approved its submission for publication.

\section{Additional material}

\section{Additional file 1}

Differentially expressed genes of the BALF-exposed A. pleuropneumoniae malT mutant, grouped according to biological role. Analyzed microarray data of the BALF-exposed A. pleuropneumoniae malT mutant.

Click here for file

[http://www.biomedcentral.com/content/supplementary/14712180-9-195-S1.doc] 


\section{Acknowledgements}

This work was supported by the grants from the Natural Sciences and Engineering Council of Canada and the Ontario Ministry of Agriculture, Food, and Rural Affairs, Canada.

We thank Drs. Jeff Caswell and Andrew Brooks for providing us with bronchoalveolar lavage fluid, and Jing Zhang and Devon Metcalf for their help with real-time PCR experiments.

\section{References}

I. Rycroft AN, Garside LH: Actinobacillus species and their role in animal disease. Vet J 2000, I 59(I): 18-36.

2. Inzana T]: Virulence properties of Actinobacillus pleuropneumoniae. Microb Pathog I99I, I I(5):305-316.

3. Bossé JT, Janson H, Sheehan BJ, Beddek AJ, Rycroft AN, Kroll JS, Langford PR: Actinobacillus pleuropneumoniae: pathobiology and pathogenesis of infection. Microbes Infect 2002, 4(2):225-235.

4. Zaas AK, Schwartz DA: Innate immunity and the lung: defense at the interface between host and environment. Trends Cardiovasc Med 2005, I 5(6): 195-202.

5. Wattiez R, Falmagne P: Proteomics of bronchoalveolar lavage fluid. I Chromatogr B Analyt Technol Biomed Life Sci 2005, 8I5(I2): $169-178$.

6. Deneer HG, Potter AA: Identification of a maltose-inducible major outer membrane protein in Actinobacillus (Haemophilus) pleuropneumoniae. Microb Pathog 1989, 6(6):425-432.

7. Dippel R, Bergmiller T, Bohm A, Boos W: The maltodextrin system of Escherichia coli : glycogen-derived endogenous induction and osmoregulation. J Bacteriol 2005, I 87(24):8332-8339.

8. Lang $\mathrm{H}$, Jonson $\mathrm{G}$, Holmgren J, Palva ET: The maltose regulon of Vibrio cholerae affects production and secretion of virulence factors. Infect Immun 1994, 62(I I):478I-4788.

9. Kumar SS, Sankaran K, Haigh R, Williams PH, Balakrishnan A: Cytopathic effects of outer-membrane preparations of enteropathogenic Escherichia coli and co-expression of maltoporin with secretory virulence factor, EspB. J Med Microbiol 200I, 50(7):602-6I2.

10. Valkonen KH, Veijola J, Dagberg B, Uhlin BE: Binding of basementmembrane laminin by Escherichia coli. Mol Microbiol I99I, 5(9):2|33-2|4|

II. Vazquez-Juarez RC, Romero MJ, Ascencio F: Adhesive properties of a LamB-like outer-membrane protein and its contribution to Aeromonas veronii adhesion. J Appl Microbiol 2004, 96(4):700-708.

12. Shelburne SA, Davenport MT, Keith DB, Musser JM: The role of complex carbohydrate catabolism in the pathogenesis of invasive streptococci. Trends Microbiol 2008, I 6(7):3 18-325.

13. Shelburne SA 3rd, Keith DB, Davenport MT, Horstmann N, Brennan RG, Musser JM: Molecular characterization of group A Streptococcus maltodextrin catabolism and its role in pharyngitis. Mol Microbiol 2008, 69(2):436-452.

14. Brunkhorst C, Andersen C, Schneider E: Acarbose, a pseudooligosaccharide, is transported but not metabolized by the maltose-maltodextrin system of Escherichia coli. I Bacteriol 1999, I 8 I(8):2612-26|9.

15. Lone AG, Deslandes V, Nash JEH, Jacques M, Maclnnes Jl: Modulation of gene expression in Actinobacillus pleuropneumoniae exposed to bronchoalveolar fluid. PLOS One 2009, 4(7):e6I39.

16. Gouré J, Findlay WA, Deslandes V, Bouevitch A, Foote SJ, Maclnnes II, Coulton JW, Nash JH, Jacques M: Microarray-based comparative genomic profiling of reference strains and selected Canadian field isolates of Actinobacillus pleuropneumoniae. BMC Genomics 2009, 1 0:88.

17. Inzana T]: Capsules and virulence in the HAP group of bacteria. Can J Vet Res 1990, 54(Suppl):S22-7.

18. Ward CK, Inzana TJ: Resistance of Actinobacillus pleuropneumoniae to bactericidal antibody and complement is mediated by capsular polysaccharide and blocking antibody specific for lipopolysaccharide. J Immunol I994, I 53(5):2 I I0-2I 2 I.

19. Bukau B, Ehrmann M, Boos W: Osmoregulation of the maltose regulon in Escherichia coli. J Bacteriol 1986, I 66(3):884-89I.

20. Kaplan JB, Mulks $\mathrm{MH}$ : Biofilm formation is prevalent among field isolates of Actinobacillus pleuropneumoniae. Vet Microbiol 2005, I 08( I-2):89-94.
21. Magnusson LU, Farewell A, Nystrom T: ppGpp: a global regulator in Escherichia coli. Trends Microbiol 2005, I3(5):236-242.

22. Potrykus K, Cashel M: (p)ppGpp: still magical. Annu Rev Microbiol 2008, 62:35-5I.

23. Srivatsan A, Wang JD: Control of bacterial transcription, translation and replication by (p)ppGpp. Curr Opin Microbiol 2008, I I (2): 100-105.

24. Balzer $G$ J, McLean $R$ : The stringent response genes relA and spoT are important for Escherichia coli biofilms under slowgrowth conditions. Can J Microbiol 2002, 48:675-680.

25. Durfee T, Hansen AM, Zhi H, Blattner FR, Jin DJ: Transcription profiling of the stringent response in Escherichia coli. J Bacteriol 2008, 190(3): 1084-1096.

26. Primm TP, Andersen SJ, Mizrahi V, Avarbock D, Rubin H, Barry CE 3rd: The stringent response of Mycobacterium tuberculosis is required for long-term survival. J Bacteriol 2000, I 82( ( 7):4889-4898.

27. Gaynor EC, Wells DH, MacKichan JK, Falkow S: The Campylobacter jejuni stringent response controls specific stress survival and virulence-associated phenotypes. Mol Microbiol 2005 , 56(I):8-27

28. Mouery K, Rader BA, Gaynor EC, Guillemin K: The stringent response is required for Helicobacter pylori survival of stationary phase, exposure to acid, and aerobic shock. J Bacteriol 2006, I88(15):5494-5500.

29. Silva AJ, Benitez JA: A Vibrio cholerae Relaxed (relA) Mutant Expresses Major Virulence Factors, Exhibits Biofilm Formation and Motility, and Colonizes the Suckling Mouse Intestine. J Bacteriol 2006, I 88(2):794.

30. Devenish J, Rosendal S, Bossé JT: Humoral antibody response and protective immunity in swine following immunization with the 104-kilodalton hemolysin of Actinobacillus pleuropneumoniae. Infect Immun 1990, 58( I 2):3829.

31. Dehio C, Meyer M: Maintenance of broad-host-range incompatibility group $P$ and group $Q$ plasmids and transposition of Tn5 in Bartonella henselae following conjugal plasmid transfer from Escherichia coli. J Bacteriol | 997, I 79(2):538-540.

32. McClelland M, Honeycutt R, Mathieu-Daude F, Vogt T, Welsh J: Fingerprinting by arbitrarily primed PCR. In Differential Display Methods and Protocols Edited by: Liang P, Pardee AB. Totowa, NJ: Humana Press; 1997:13-24.

33. Peng H: High-resolution Sscp analysis using polyacrylamide agarose composite. Biotechniques 1995, 19:410.

34. Baltes N, Tonpitak W, Hennig-Pauka I, Gruber AD, Gerlach GF: Actinobacillus pleuropneumoniae serotype 7 siderophore receptor FhuA is not required for virulence. FEMS Microbiol Lett 2003, 220( I):41-48.

35. Oswald W, Tonpitak W, Ohrt G, Gerlach G: A single-step transconjugation system for the introduction of unmarked deletions into Actinobacillus pleuropneumoniae serotype 7 using a sucrose sensitivity marker. FEMS Microbiol Lett 1999, I79(I): I53-160.

36. Deslandes V, Nash JH, Harel J, Coulton JW, Jacques M: Transcriptional profiling of Actinobacillus pleuropneumoniae under iron-restricted conditions. BMC Genomics 2007, 8:72.

37. Carrillo CD, Taboada E, Nash JH, Lanthier P, Kelly J, Lau PC, Verhulp R, Mykytczuk O, Sy J, Findlay WA, Amoako K, Gomis S, Willson P, Austin JW, Potter A, Babiuk L, Allan B, Szymanski CM: Genomewide expression analyses of Campylobacter jejuni NCTCI I 168 reveals coordinate regulation of motility and virulence by flhA. J Biol Chem 2004, 279( I 9):20327-20338.

38. Saeed Al, Sharov V, White J, Li J, Liang W, Bhagabati N, Braisted J, Klapa M, Currier T, Thiagarajan M, Sturn A, Snuffin M, Rezantsev A, Popov D, Ryltsov A, Kostukovich E, Borisovsky I, Liu Z, Vinsavich A, Trush V, Quackenbush J: TM4: a free, open-source system for microarray data management and analysis. Biotechniques 2003, 34(2):374.

39. Schmittgen TD, Livak KJ: Analyzing real-time PCR data by the comparative C(T) method. Nat Protoc 2008, 3(6): I I0 I-I I 08. 